\title{
Deixa a gira girar: as lives de Teresa Cristina em tempos de escuta conexa ${ }^{1}$
}

Jeder Silveira Janotti Junior

https://orcid.org/0000-0003-3975-7433

\section{Tobias Arruda Queiroz"}

https://orcid.org/0000-0001-9311-846X

I - Universidade Federal de Pernambuco. Recife (PE). Brasil.

II - Universidade do Estado do Rio Grande do Norte. Natal (RN). Brasil.

Resumo: Este artigo observa como a música pode servir de vetor para os processos de narrativização e mediação dos aspectos estéticos, políticos, socioculturais e tecnológicos agenciados por artistas, oriundos do universo musical, em ambientes de mídias de conectividade. Esse trajeto nos permitiu observar como a narrativização da escuta nas lives de Teresa Cristina no Instagram acabou por desvelar o marcado jogo de gênero, raça e territorialidade que atravessam o universo artístico brasileiro, apontando para novas possibilidades de configuração das lives musicais em plataformas on-line quando observadas através das lentes do ecossistema de mídias de conectividade.

Palavras-Chave: escuta conexa; lives; Teresa Cristina; Instagram.

\footnotetext{
Abstract: “Deixa a gira girar" (Lets the spin spin): Teresa Cristina's lives in connected listening times - This paper seeks to observe how music can serve as a vector for the processes of narrativization and mediation of aesthetic, political, socio-cultural, and technological aspects by artists from the musical field in environments of connectivity media. In this sense, we observed how the connected listening in Teresa Cristina's lives ended up highlighting 
gender, race, and territoriality issues in the Brazilian artistic universe. This analysis points to new possibilities of experiencing musical lives on online platforms when viewed through the lens of connectivity media's ecosystem.

Keywords: connected listening; lives; Teresa Cristina; Instagram.

\section{Introdução}

Ao longo dos últimos anos, praticamente todas as formas de expressão cultural foram contaminadas pelas modulações das redes sociais. Com o universo da música não foi diferente. Além das mudanças nos modos de produzir, acessar e consumir música, as dinâmicas da presença de artistas musicais nas redes alteraram a própria escuta musical. Devido ao isolamento social vivido em tempos de Covid-19, as lives de música on-line acabaram por substituir parte do consumo presencial de música ao vivo. Apesar de reconhecermos que as gramáticas das lives das redes sociais atravessaram o mundo da música, acreditamos que os modos de vivenciar a música e, consequentemente, de configurações das lives de música são acionados no imbricamento entre práticas oriundas do universo da música gravada e o ecossistema de mídias de conectividade.

A partir dessa premissa, este artigo se divide em duas partes distintas, mas complementares. Na primeira, a partir do redimensionamento da escuta musical, propomos o conceito de escuta conexa como forma de observar, ao mesmo tempo, os aspectos estéticos, socioculturais e tecnológicos da escuta em tempos de ambientações de mídias de conectividade. Essa proposição é acionada a partir da ideia de que, além dos aspectos sensórios presentes na audição musical, os atos de ouvir ou audiovisualizar música são práticas sinestésicas que ocorrem a partir de narrativizações que agenciam música, tessituras biográficas e acoplagens tecnológicas dessas narrativas. Pois acreditamos que a junção de conhecimentos oriundos dos Estudos Culturais com Estudos de Ciência e Tecnologia permitem que evitemos isolar a escuta de música como fenômeno social ou como práticas observadas apenas a partir de suas moldagens tecnológicas. Assim, observar a configuração da música em tempos de ecologia das mídias de conectividade é uma oportunidade para perceber como as questões de gênero, raça e territorialidade são articuladas no universo da música.

Na segunda parte do artigo, acionamos as discussões efetivadas em torno da ideia de escuta conexa para analisar as lives da cantora Teresa Cristina nas 
plataformas Instagram e YouTube. Assim, além de abordar o modo como Teresa Cristina se aclimatou aos tempos de lives de música on-line, virando referência estético-política nessa ambientação, procuramos compreender como as narrativizações da escuta articulam os aspectos estético-políticos e socioculturais da música em ambientações de mídias de conectividade.

\section{Narrativização e mediação na escuta conexa}

No advento da música gravada, observou-se com grande espanto - hoje já normatizado - a ideia de ouvir música incorpórea, ou seja, sem estar diante dos corpos que executavam a música. Alguns autores, como o canadense Raymond Murray Schaffer (1991), cunharam termos como esquizofonia para este processo de escuta, que transformou a audição musical, mediada por aparelhos eletroeletrônicos, em algo fantasmagórico. Após mais de um século de reprodução de música, acostumamo-nos com a ideia de que a escuta é da ordem da hegemonia da audição, deixando de lado o fato de que, antes da música gravada, a escuta musical era um acontecimento sinestésico, afinal, a audição musical pressupunha a presença de corpos tocando música ao vivo, fato que voltou a ser reverberado a partir das íntimas relações entre música e cinema e, posteriormente, com a afirmação do videoclipe como um dos produtos centrais para a divulgação musical, a partir dos anos 1980.

Assim, há de se observar diferenças entre as dimensões sonoras da música quando observadas em sentido estrito e os aspectos narrativos do consumo musical. Baseado em Pierre Schaffer, o pesquisador brasileiro Giuliano Obici (2008, p. 27) afirma: "Sonoro seria o perceptível, aquilo que se capta, diferente de musical, que seria um juízo de valor atribuído ao som". Mesmo que ainda atrelada às definições de escuta como fenômeno físico-psíquico auditivo, a descrição acima permite-nos pensar na impossibilidade de retalhar os desdobramentos estéticos, sociais e tecnológicos do consumo musical, na ambientação comunicacional contemporânea.

Dessa forma, os modos como a ambientação tecnológica entrelaça as modulações musicais apontam para a importância de se abordar a escuta como agenciamento entre música, tecnologia e relações sociais. É nessa direção que a escuta pode ser pensada como corporalidade em ambientações tecnológicas, tal como propõe Anahid Kassabian: 


\begin{abstract}
essas tecnologias vozes, instrumentos, sistemas de som ou iPods e outros dispositivos de escuta. Isso apaga, imediatamente, a distinção corriqueira entre escutar e ouvir que muitas vezes se faz, sob a presunção de que ouvir é fisiológico e escutar é consciente e atento (KASSABIAN, 2013, p. 325, tradução nossa).
\end{abstract}

Apesar da importante virada para suplantar as divisões de apelo fisiológico que as possíveis distinções entre os atos de ouvir e escutar ainda carregam, cabe-nos apontar que a presença das interações entre corpo e tecnologia - as corporalidades na escuta - devem ser incorporadas tendo em vista que aspectos sinestésicos das escutas musicais se desdobram através de tessituras da intriga acopladas ao ato de escutar música.

Por que mantermos a ideia de escuta, uma vez que se parte do reconhecimento da ativação de outros sentidos no consumo musical? Bem, nosso pressuposto é que, ao longo da história da música gravada, expressões ditas não musicais foram abalizadas a partir do universo da música, ou seja, biografias, entrevistas, presença nas redes sociais e atuações em outros universos culturais, quando encenadas por artistas musicais, têm como fio condutor ambiências do mundo da música. Essas ambientações são compreendidas como mediações (malhas elásticas, pervasivas e conexas) que delimitam e transformam a materialidade da produção, circulação, consumo e apropriação do que se nomeia como música.

No caso da escuta musical, as mediações são processos de materialização de engajamentos em ambiências do mundo da música em seus aspectos estéticos, socioculturais e tecnológicos.

Mediação, nesse sentido, descreve uma casualidade não-linear; mapeia fluxos, interrupções e paradas que descrevem o devir ou autoprodução da realidade ou melhor, realidade-sempre-configurada. Mediação é o movimento de eventos ou corpos de um conjunto de relações para outras como se elas estivessem constantemente transformandose em alguma coisa diferente do que são. É o espaço entre o virtual e o atual, o tornar-se atual (GROSSBERG, 2010, p. 191, tradução nossa).

Nesse cenário, propomos a ideia de escuta conexa como um modo de abordar a escuta musical no ambiente comunicacional contemporâneo. Para isso, torna-se indispensável levar em conta as mediações estéticas, socioculturais e tecnológicas operadas no consumo musical em diferentes ambiências e 
formatações. Nessa direção, acreditamos que tais mediações são articuladas nos processos de territorialidade narrativa e conectividade.

Para pensar a territorialidade da escuta musical, fomos instigados pelo pensamento da poetisa e pesquisadora zimbabuense, Tsitsi Ella Jaji (2014), que aborda a partir da escuta as mediações estético-políticas na música, cinema, poesia e tecnologias de reprodução musical na África do Sul, Gana e Senegal:

Ouvir atentamente não diminui o valor do visual ou dos outros sentidos, antes treina nossa atenção sobre a circulação de significados entre nossos sentidos, lembrando-nos como é artificial imaginar que cada sentido é autônomo. Esse sentido de ouvir como abertura de outros canais sensoriais e imaginativos ressoa no estereomodernismo como um relato de como a música ativa outros campos da produção cultural (JAJl, 2014, p. 19, tradução nossa).

Jaji usa a ideia de estereomodernismo não só para enfrentar os aspectos colonialistas que sustentam as epistemologias eurocêntricas da modernidade, mas também como modos de habitar o mundo onde os campos de produção cultural podem se interpenetrar e sobrepor-se através de suas ativações pelo universo da música.

Para amplificar o alcance das mediações estético-políticas de Tsitsi Ella Jaji, valemo-nos da ideia de territorialidades narrativas, proposta por Mehita Iqani e Fernando Resende (2020). Assim, a partir da noção de escuta como ato conexo, é possível abordar a territorialidade da música como senso de pertencimento que acionam os fluxos musicais através de complexas mediações culturais:

[...] o sul global pode ser conceitualizado como inscrito dentro de uma "territorialidade narrativa". O objetivo é entender questões de mídia e do sul global como, de fato, sendo constitutiva e constituinte desta (dentro e desde) territorialidade, o que quer dizer que a mídia não somente se inscreve em um território (o sul global) mas também é responsável por produzir narrativas sobre isso (IQANI; RESENDE, 2020, p. 7, tradução nossa).

Nessa direção, a proposição da articulação das mediações da escuta conexa às ideias de Jaji (2014), Iqani e Resende (2020) não é ocasional ou aleatória, e sim parte da perspectiva de que a compreensão aprofundada dos ecossistemas de mídias de conectividade é atravessada por questões de gênero, raça e território. Daí a proposição de escuta conexa como um 
modo de perceber como as audições e audiovisualidades, acionadas a partir do universo musical, desdobram-se em tessituras dos processos de escuta que recortam o mundo não só pelas ambientações tecnológicas, bem como pela materialidade dos corpos e territórios acionados nesse ecossistema. Assim, junto à proposta de José Van Dijck (2013), pensamos uma ecologia comunicacional que, além de levar em conta a escuta musical no ecossistema de mídias de conectividade, também observa as diferentes possibilidades de habitar esse universo.

Se o objetivo é entender como, no período em causa, a sociedade online desenvolveu-se, não basta estudar plataformas individuais; em vez disso, nós precisamos apreender como elas coexistem em um largo contexto de plataformas interconexas e dissecar a lógica cultural subjacente a esse processo. Assim, eu proponho olhar para distintas plataformas como microssistemas. Todas as plataformas combinadas constituem o que eu chamo de ecossistema de mídias de conectividade - um sistema que alimenta e, por sua vez, é alimentado por normas sociais e culturais que se expandem simultaneamente em nosso mundo cotidiano. Cada microssistema é sensível a mudanças em outras plataformas do ecossistema: se o Facebook altera suas configurações de interface, o Google reage alterando seus ajustes de plataformas, se a participação na Wikipédia diminuir, os recursos algorítmicos do Google podem fazer maravilhas (VAN DIJCK, 2013, p. 21, tradução nossa).

Acrescentamos que tanto o ecossistema de mídias de conectividade, como os microssistemas das plataformas em suas singularidades não funcionam somente em articulações observadas na ambiência digital, bem como nas modulações dessa ambiência através das questões de gênero, raça e territorialidade.

Nesse contexto, adicionar às dimensões da escuta as ideias de territorialidade e conectividade possibilita-nos incorporar aos atos de ouvir música tanto a presença dos artefatos de consumo musical quanto os engajamentos heterogêneos que a integram: videoclipes, entrevistas, apresentações ao vivo, lives, biografias e modos de acesso aos conteúdos em streaming, através dos aplicativos das plataformas digitais, sem desconsiderar as mediações socioculturais que perpassam os aspectos estéticos e tecnológicos do ecossistema de mídias de conectividade.

É nesse cenário que procuramos acionar a escuta conexa para compreender a configuração das lives de Teresa Cristina no Instagram e no YouTube 
como amplificação do universo musical para a ancoragem de questões de raça, gênero e territorialidade. Faz-se importante notar, como será visto na segunda parte do artigo, que a escuta conexa pressupõe a articulação de pelo menos três instâncias de configuração narrativa: a narrativa da trajetória de artistas musicais em diferentes ambiências; as mediações em conectividade dessas narrativas; e a tessitura desses processos a partir da escuta musical.

O sucesso de Teresa Cristina nas redes sociais nos parece singular para refletir sobre a escuta conexa pois, antes da pandemia, a cantora não parecia tão afeita ao ecossistema de mídias de conectividade. Do início, de maneira tímida no Instagram, valendo-se das limitações da plataforma, até a veiculação de lives musicais no YouTube sob o patrocínio da cerveja Original, a trajetória de Teresa Cristina nas redes sociais acabou por torná-la um marco na articulação entre diferentes modulações políticas, estéticas e sociais, a partir da ambientação comunicacional da música em tempos de plataformas online.

\section{As lives de Teresa Cristina: ecossistemas midiáticos possíveis}

A pesquisadora Luciana Xavier (2020) apontou em uma outra oportunidade que as lives no Brasil são, para nós, algo semelhante ao que alguns países europeus vivenciaram e expuseram a partir das suas varandas. Ou seja, nas lives sociabilizamos, dialogamos e encontramos uma forma adicional de ter a sensação de coletividade, de pertencimento. Essa sensação acionada pela escuta conexa teve o seu auge principalmente nos primeiros meses do isolamento social imposto pela Covid-19.

Exemplos não faltam. As lives musicais na plataforma YouTube se tornaram um grande frenesi desde o início da pandemia. Podemos extrair momentos surpreendentes e bem estruturados, como a apresentação patrocinada pelo canal da Brahma no Youtube de Zeca Pagodinho no dia dos pais (UOL, 2020a), ou a superaudiência de Marília Mendonça com recorde mundial de acessos simultâneos (FONTES, 2020).

É importante assinalar que, apesar da modalidade de audiência em conectividade que caracteriza as lives musicais na plataforma YouTube, elas seguem em sua maioria o padrão que já havia sido estabelecido pela TV broadcasting, ou seja, são transmissões ao vivo de apresentações musicais em formato tradicional, nas quais artistas performam sob a perspectiva de 
um palco italiano, diante de uma audiência virtual. Apesar da ausência física de público, muito das angulações, da distribuição de músicos em cena, iluminação, mixagem sonora e dinâmica cênica segue os padrões esperados de uma transmissão da apresentação ao vivo de música na TV, só que agora ao vivo, on-line, na dinâmica da ecologia de mídias de conectividade.

Essa presença do YouTube como vetor do consumo de música ao vivo on-line não é novidade. Desde seu surgimento, em 2005, além de servir de repositório para imagens de shows ao vivo, a plataforma já tinha transformado a modulação da música ao vivo com o sucesso das postagens de gravações de trechos de shows em celulares, articulando os aspectos profissionais de gravações de música ao vivo, estabelecidos pelo cinema e pela televisão, com os aspectos intimistas e instantâneos das gravações a partir dos smartphones. Por isso mesmo surpreende o fato de o Instagram - e não o YouTube — ter sido a rede em que primeiro se destacaram as lives musicais on-line durante a pandemia. A primeira live musical de sucesso foi o festival português \#euficoemcasa, uma série de apresentações musicais transmitidas no Instagram ainda em março (JANOTTI JUNIOR; PIRES, 2021).

É nesse cenário que passamos a notar as singularidades na trajetória de sucesso das lives da cantora/compositora Teresa Cristina. As lives da cantora no Instagram destoaram do protagonismo exercido pelo YouTube para a veiculação e consumo de música ao vivo on-line. Tratando-se de uma plataforma cujo microssistema é assentado na postagem instantânea de textos curtos e imagens, a interação no Instagram segue dinâmicas diferentes do YouTube. Apesar de parecer pouco quando comparado aos números do YouTube, o crescimento da quantidade de seguidores de Teresa Cristina, levando-se em conta o antes e o depois do início das lives diárias no Instagram, é bastante expressivo para a ambiência dessa plataforma. Antes a cantora tinha 98 mil seguidores, número que hoje ultrapassa os 350 mil (TERESA CRISTINA, 2020).

É importante frisar que ao longo da consolidação do epíteto de rainha das lives $^{2}$ atribuído à Teresa Cristina, ela demonstrou uma contínua capacidade de se valer do microssistema específico dessa plataforma, ou seja, ela acabou se valendo da precariedade da imagem e som ao vivo captados pelo telefone celular, característica técnica das transmissões ao vivo do Instagram. Nessa ambiência Teresa Cristina firmou-se, a partir do canto à capela, sem

2 Título utilizado amplamente pela mídia, principalmente a impressa. Em uma rápida pesquisa, localizamos no dia 7 de maio de 2020, na Folha S. Paulo, uma das primeiras menções a Teresa Cristina como a "rainha das lives". Mais detalhes disponíveis em: <tinyurl.com/yxu53c2g>. Acesso em: 28 mai. 2021. 
acompanhamento de outros músicos e instrumentos. Essa particularidade acabou por se desdobrar também nas características imagéticas da lives da cantora no Instagram, já que os enquadramentos pelas câmeras de celulares, otimizadas para o registro de selfies, tendem a privilegiar o primeiro plano, com enquadramentos mais fechados e foco na face da usuária/usuário. Os jogos com essas mediações imagéticas são bem diferentes da emulação das transmissões televisas broadcastings operadas pela qualidade sonora e diversidade de enquadramentos das lives musicais exibidas nos canais de artistas, redes televisivas e cervejarias no YouTube.

É importante lembrar que até 2020, apesar de mais de 22 anos de carreira, Teresa Cristina não era reconhecida por sua atuação nas ambientações digitais, já que atuava no circuito de shows e era conhecida pelo álbum A música de Paulinho da Viola (2002), que Ihe rendeu sucesso para além da cena musical da Lapa, no Rio de Janeiro, onde as apresentações da artista acabaram por se tornar referência da revitalização do bairro e do samba na cidade. É nesse contexto que Teresa Cristina ganhou a alcunha "cantora de samba", que, apesar de fazer jus à sua afirmação como uma cantora negra, pode reduzir o amplo leque de sua atuação anterior ao sucesso de suas lives na plataforma Instagram. Shows e álbuns aclamados, como Teresa canta Cartola (2016) e Teresa canta Noel (2018), salientam sua reverência ao samba. De outro lado, álbuns como Teresa Cristina + Os outros = Roberto Carlos (2012) já mostravam a capacidade da artista de transitar por universos mais amplos, a partir de outras modulações musicais.

Assim, restringir a carreira de Teresa Cristina à alcunha "cantora de samba" pode soar como um movimento de diminuição da sua voz, algo recorrente nas tentativas de enquadrar artistas negras/os no campo de categorizações musicais tradicionais. Seu repertório musical nas lives abriga desde os grandes sucessos da soul music norte-americana, passando por "temas de novelas", canções de referência da MPB e, como não poderia deixar de ser, pelo samba. Assim, mesmo que se possa afirmar uma certa adequação entre as interpretações à capela de canções de samba, atrelada à forte presença do rosto de Teresa Cristina em primeiro plano no Instagram, o cardápio musical das apresentações da cantora na plataforma esteve longe de ser restrito a um único gênero musical. Muitas vezes, esse repertório é desenrolado em narrativizações de marcos temporais, que são acionados para celebrar aniversários ou fazer homenagens a artistas como Caetano Veloso, Djavan, Gilberto Gil, Chico Buarque, Elis Regina, Gal Costa; tributos a Eddie Van Halen e ao Rock Brasil; e/ou em torno de datas comemorativas, como orgulho LGBTQIA+, Nordeste, samba de roda do Recôncavo Baiano. 
Em entrevista ao podcast Novo Normal, a cantora explica que suas lives começaram como uma forma de proporcionar aconchego a sua mãe durante o tempo de pandemia (A QUARENTENA, 2020). Como Dona Hilda, mãe de Teresa Cristina, sempre teve o desejo de ser cantora, surgiu a ideia de escolher algumas músicas. Dessa forma, ela começou a se apresentar em dupla com a mãe no canal da cantora no YouTube, à capela, ou seja, só com a força de suas vozes, sem acompanhamento de outros instrumentos musicais. Ao contrário das apresentações profissionais, que começavam a inundar o YouTube, Teresa Cristina e Dona Hilda ${ }^{3}$ apareceram primeiramente em uma produção caseira, sentadas diante da câmera do computador, enquanto Teresa Cristina buscava se aclimatar à plataforma naquele domingo de Páscoa de 2020, ajeitando foco, luz e angulação em uma transmissão tipicamente artesanal.

Durante uma das primeiras lives com a mãe no YouTube, surgiu um comentário no chat sobre como se caracterizaria o "samba de terreiro". Teresa Cristina percebeu que, para responder o que era "samba de terreiro" a partir do questionamento na live no YouTube, ela gastara muito tempo "twittando" com seus seguidores. A partir daí, a cantora teve a ideia de fazer uma live no Instagram, com as pesquisas feitas, para explicar o "samba de terreiro". Como disparador da narrativização das lives de Teresa Cristina, observamos nesse evento o modo como a mediação da ambiência musical fez-se a partir da presença de um território de pertencimento, "samba de terreiro", engendrado a partir da escuta conexa, em que o fato de ser reconhecida como cantora/compositora negra de samba acabou se amplificando para a tessitura, em que o acionamento do comentário de um fã acabou por amplificar Teresa Cristina nos papéis de pesquisadora/intérprete da trajetória arquival do samba, desdobramento fortemente afinado com os aspectos interativos da ecologia de mídias de conectividade.

A partir dessa tessitura da conectividade on-line, Teresa Cristina começou a fazer suas lives diárias no Instagram em encontros ritualísticos sempre às 22h; depois, no fim de setembro, o horário foi alterado para as $20 \mathrm{~h}$. Mesmo com a mudança de horário e a desenvoltura que hoje Teresa Cristina demonstra ao atuar no Instagram, o modus operandi das suas lives ainda parece ancorado naquela primeira apresentação ao vivo, com Dona Hilda, no YouTube. Aparentemente, não há engessamento, as apresentações são

\footnotetext{
3 A live de estreia foi transmitida em 12 de abril de 2020 e pode ser acessada no canal oficial da cantora no YouTube. Disponível em: <https://www.youtube.com/channel/UCrs_t3HCEvhynFEll2fY1 FW>. Acesso em: 25 mar. 2021.
} 
cheias de improvisos, no entanto, sempre com o mesmo cuidado, como Teresa Cristina enuncia em suas apresentações: temas pré-definidos, músicas e letras selecionadas, pesquisadas e disponíveis, mas que podem ganhar outras rotas, a partir da interação em conectividade com o público e as/os convidadas/os da artista.

É interessante notar que uma característica das lives produzidas a partir da ergonomia dos smartphones acabou por acionar outras narrativizações de identificação por parte da cantora. Quando se viu refletida no espelho das telas a partir do enquadramento em primeiro plano das selfies, Teresa Cristina notou que, ao contrário do que acontecia nos shows ao vivo tradicionais, nas lives artesanais não havia a ilusão do palco italiano: "vocês podem até achar graça, mas eu canto olhando para mim" (A QUARENTENA, 2020). Até então, parecia-lhe que o espelho era útil para preparar-se antes de cantar, mas não como modo de encarnar a corporalidade daquela que canta. Talvez essa seja uma das chaves para se imaginar porque a temática da negritude tornou-se uma das narrativas modulares das lives de Teresa Cristina no Instagram.

A forte presença articulada do rosto, do design de cabelos, bijuterias e do canto negro de Teresa Cristina acabaram por se constituir como uma potente assinatura da escuta conexa de suas músicas nas lives do Instagram, demonstrando como é possível pensar as mediações de raça e gênero ambientadas através dos microssistemas das mídias de conectividade, ou seja:

Trata-se, portanto, de compreendermos como as práticas se dão a partir dos usos possíveis, planejados ou não, das interfaces em suas funcionalidades. Em cada situação, abre-se um leque potencialmente amplo - mas não ilimitado - de ações possíveis (D'ANDRÉA, 2020, p. 738).

Essa reversão do mito de Narciso - que, como nos lembra Grada Kilomba (PINACOTECA DE SÃO PAULO, 2019), é uma beleza grega, uma beleza, portanto, branca - não se reduziu ao acionamento de música negra ou de temáticas relacionadas às questões raciais no Brasil, mas se espraiou na corporalidade das lives de Teresa Cristina e no modo como ela agenciou suas lives na plataforma Instagram.

A narrativização das pautas raciais levantadas nas lives da cantora segue a microambientação do Instagram, utilizando modulações tecnoestéticas da plataforma para agenciar as questões de raça, ancoradas em seu repertório 
de canções. Teresa Cristina mostra indignação com as mortes de George Floyd, nos Estados Unidos, ou do menino Miguel, em Recife, amplificando o espaço das canções para a ambientação dos trending topics, que marcam a ecologia das mídias de conectividade. Em um bate-papo com a tela duplicada, característica da plataforma Instagram quando mais de uma pessoa participa da transmissão, Alcione critica frontalmente o ocupante do cargo de presidente da Fundação Palmares, Sérgio Camargo. "Ele é um Zé Ninguém”, disse a cantora maranhense (UOL, 2020b). Fala de racismo com Antonio Pitanga. Canta sambas de Umbanda - dia com maior audiência streaming até então, acima de 6 mil pessoas.

Como pontuado, a narrativização desses temas ocorre através da acoplagem entre o repertório musical e os modos de criar e projetar mundos nas ecologias das mídias de conectividade. Assim, os sambas de umbanda são acoplados de forma conexa às ambientações comunicacionais da plataforma Instagram, amplificando as discussões em rede, pontuadas por posicionamentos políticos, como comentários sobre as polêmicas (em rede) apontadas por Sérgio Camargo, que usualmente se vale da plataforma Twitter para alardear suas polêmicas contra personalidades da comunidade negra brasileira.

De outro lado, mas somando-se às narrativizações de sonoridades da Umbanda, Teresa Cristina conecta-se às comemorações do aniversário de Antônio Pitanga, referência do movimento negro. É interessante notar que nessa live o cantor Chico Buarque, amigo de Pitanga, pontuou que aquela era sua primeira live e assinalou sua decepção com a impossibilidade de estar na tela ao mesmo tempo que Teresa Cristiana e o aniversariante do dia, nomeando assim os limites e a poética da ambientação do Instagram.

Em 5 de outubro de 2020, a temática da live foi Laroyê Exu! Luiz Antonio Simas, encontro marcado com pontos de macumba, sambas para Zé Pilintra, salve para Pombagira e Tranca-ruas. Essa noite nos fez pensar como as músicas cantadas por Teresa Cristina em suas lives agenciam narrativizações em múltiplos sentidos, que envolvem a interpretação das canções, a interação da cantora com convidadas/convidados e fãs, que publicam seus comentários ao longo da live. Mais uma vez, vemos o acionamento de diferentes mediações a partir das interpretações musicais, agenciadas por frutíferas discussões com o próprio Simas, explanações, diálogos, conversas, risos, choros, atravessados por uma agenda calcada fortemente no tripé de identificação, raça e gênero, a partir da plasticidade da plataforma Instagram. 
Ao falar de raça, por exemplo, Teresa Cristina, que é umbandista, dialoga com a cultura negra em várias frentes. Por essa razão, o espraiamento de seu canto em ambientações de mídias de conectividade acaba por acionar um elemento central da escuta conexa: a interatividade que acaba por reconfigurar os próprios modos de acionar a umbanda, as canções de samba e os comentários em rede.

Assim, destaca-se o papel dos cristiners ${ }^{4}$ nessa tessitura. Nascido de um grupo de WhatsApp, o fã-clube cristiners acabou por migrar para o Instagram, após uma provocação de Jéssica da Costa Pinheiro, uma “mulher negra não retinta e lésbica5", que concilia o papel de presidenta do primeiro fã-clube de Teresa Cristina ao de estudante da pós-graduação em Educação de Jovens e Adultos pelo IFRJ. A conexão entre o fã-clube e Teresa Cristina é alimentada cotidianamente com funções delimitadas através de grupos de trabalho. Assim, há quem produza textos para postar na página; há as responsáveis pelas escolhas de mimos a serem enviados à Teresa, bem como pela escoIha das comidas e das bebidas que são enviadas todas as noites para a rainha das lives. Inclusive, diz Jéssica, "já realizamos movimentos para Teresa Cristina conseguir mais inscritos no canal do YouTube, com o objetivo de realizar a primeira live patrocinada" (a plataforma exige um mínimo de mil inscrições para que seja possível realizar uma transmissão ao vivo). A energia que move os cristiners também gira em torno de como a própria Teresa Cristina gerencia suas interações na ecologia das mídias. Em entrevista ao O Globo, ela comenta que uma das suas estratégias é "falar também sobre temas muitas vezes desprezados pela intelectualidade, como o BBB. É uma forma de ter contato com pessoas que eu jamais conheceria" (GOBBI, 2020).

Enfim, o envolvimento do público e dos fãs também pode ser constatado em outros acontecimentos e acionamentos, desde o gatilho disparado pelas perguntas sobre o "samba de terreiro" que dá início às lives no Instagram, até as ações do fã-clube cristiners, incluindo um mutirão em busca de votos para o prêmio Miaw 2020, da MTV, no qual Teresa Cristina foi finalista na categoria Live pra tudo, junto a Fábio Porchat, Chico Salgado, Bianca Andrade (vencedora) e Matheus Mazzafera. Aqui pode-se notar que, diferentemente da emulação de transmissão de apresentações de música ao vivo, que caracterizam as lives de sucesso no YouTube, as lives de Teresa Cristina acionam a ambientação musical, mas são amplificadas pela ideia de ao vivo do microssistema de mídias de conectividade do Instagram.

4 O perfil no Instagram do fã-clube conta com mais de 7.500 seguidores (CRISTINERS OFICIAL, 2020). Segundo Jéssica, hoje há cerca de 40 pessoas envolvidas diretamente com as atividades dos cristiners.

5 A entrevista foi realizada via WhatsApp, em 18 de janeiro de 2020. 
Afinal, as narrativizações que caracterizam as mediações presentes nas escutas conexas pressupõem vínculos estabelecidos como sentimento de pertença, acionados pela música através do envolvimento conjunto de artistas e ouvintes, amplificando a espacialidade sinestésica das escutas musicais para a constituição de territorialidades vividas em ambiências comunicacionais de mídias de conectividade.

\section{Conclusões}

A moldagem política das lives de Teresa Cristina não deve, nem há como, ser visualizada de forma desconectada das interpretações à capela de Teresa Cristina. Seu roteiro não se restringe à música, mas se desenrola a partir dessa ambiência, conectando-se tanto aos aspectos macro da ecologia das mídias de conectividade, quanto ao microssistema da plataforma Instagram. Esses limites acabaram por se transformar em intensidade, pois, ao invés de uma live musical on-line profissional, no padrão dos sucessos do YouTube, esses encontros de conectividade em torno da cantora acontecem no acionamento de aspectos das interpelações das lives não musicais, como o tom intimista de uma roda de samba de boteco on-line, amplificada no rol das canções que se abrem como aconchego e acalanto para os que se encontram com Teresa Cristina no Instagram:

[...] Não entre lá desavisado [nas lives no Instagram]. Aliás, nem passe perto se você for do tipo que acha normal o que está acontecendo no País. Certamente, será bloqueado, ou se sentirá confuso com tamanha força dos discursos antirracistas, anti-homofóbicos e antiBolsonaro (LIMA, 2020).

As narrativizações da escuta nas lives de Teresa Cristina acabaram por desvelar outras possibilidades de adentrar no marcado do jogo de gênero e raça que se desenvolve no universo artístico brasileiro. O próprio desenrolar das lives da cantora no Instagram ressonou em seus lugares de pertença, intensificando e potencializando suas territorialidades. "Percebi que a melhor parte do meu dia era essa, é um lugar de acolhimento e afago, onde esqueço da Covid e dos desmandos políticos do país" (GOBBI, 2020), diz a cantora.

Em maio de 2020, Teresa Cristina comemorou o patrocínio de sua primeira live no YouTube, posicionando-se: "sou invisível desde 1988" (SARMENTO, 2020). A primeira ação patrocinada em sua carreira aconteceu no dia 30 de maio de 2020, após 22 anos de atividade profissional. Ainda assim, mesmo 
após ter sido, finalmente, alçada ao panteão das artistas com direito a eventos ao vivo, on-line, nos canais das cervejarias no YouTube, Teresa Cristina não parece cansada de guerra. Ela continua a territorializar sua alacridade diariamente, valendo-se da intimidade adquirida durante esse tempo na difícil arte de conjugar questões sociais, de raça e gênero, através da escuta conexa de seu repertório musical. Se, no início, Teresa Cristina parecia tatear as transformações de suas vivências nas lives do Instagram, com o passar do tempo ela acabou por se aclimatar às ecologias das mídias digitais, especialmente da microambientação do Instagram, acionando questões de raça e gênero em suas lives, a partir da música modulada por novos modos de escuta em tempos de mídias de conectividade.

Jeder Silveira Janotti Junior é professor do Programa de Pós-graduação em Comunicação da Universidade Federal de Pernambuco, onde coordena o Laboratório de Análise de Música e Audiovisual (L.A.M.A.). É pesquisador do CNPq.

jederjr@gmail.com

Tobias Arruda Queiroz é professor de jornalismo da Universidade do Estado do Rio Grande do Norte e pesquisador do Laboratório de Análise de Música e Audiovisual da UFPE.

tobiasqueiroz@gmail.com

Contribuições de cada autor: o artigo foi produzido dentro do âmbito do projeto de pesquisa "Por uma abordagem comunicacional dos gêneros musicais" (Bolsa PQ, (NPq), de Jeder S. Janotti Junior. O projeto é parte integrante do Laboratório de Análise de Música e Audiovisual do PPGCOM/UFPE, coordenado por esse pesquisador, em que Tobias Arruda Queiroz também atua como pesquisador. $\mathrm{O}$ artigo foi produzido conjuntamente pelos dois pesquisadores, que dividiram de forma equânime os processos de redação, finalização da escrita e revisão da primeira versão do artigo. Levando-se em conta as contribuições específicas de cada um dos autores, Jeder $\mathrm{S}$. Janotti Junior teve maior participação na construção das investigações bibliográficas, na fundamentação teórica e conceituação; enquanto Tobias Arruda Queiroz dedicou-se 
mais intensamente à investigação de campo e análise do corpus. A produção do artigo e da pesquisa contou com apoio do CNPq através de Bolsa de Produtividade PQ e da Capes através de recursos do Programa de Apoio à Pós-Graduação (PROAP).

\section{Referências}

A QUARENTENA das lives. Entrevistadores: Antonia Pellegrino e Manoela Miklos. Entrevistada: Teresa Cristina. Brasil: Spotfy, 1 jun. 2020. Podcast. Disponível em: <https://open. spotify.com/episode/0wrjisjAjqZwn3aF5Cvd7V?si=eXz4yNejR4iXULeropfuww\&nd=1>. Acesso em: 11 out. 2020.

CRISTINERS OFICIAL. Perfil Instagram, 2020. Disponível em: https://www.instagram.com/ cristinersoficial/?igshid=nt6ka5avs0ej. Acesso em: 19 ago. 2020.

D'ANDRÉA, C. Pesquisando plataformas online: conceitos e métodos. Salvador: Edufba, 2020.

FONTES, M. Marília Mendonça bate recorde mundial em live. Folha de Pernambuco, 8 abr. 2020. Disponível em: https://www.folhape.com.br/cultura/marilia-mendonca-bate-recorde-mundial-em-live/136625/. Acesso em: 10 out. 2020.

GOBBI, N. 'Cristiners': Lives de Teresa Cristina reúnem anônimos e famosos na madrugada. O Globo, 19 abr. 2020. Cultura. Disponível em: https://oglobo.globo.com/cultura/musica/ cristiners-lives-de-teresa-cristina-reunem-anonimos-famosos-na-madrugada-1-24381889.. Acesso em: 18 jan. 2020.

GROSSBERG, L. Cultural studies in the future tense. Durham, London: Duke University Press, 2010.

IQANI, M.; RESENDE, F. Media and the global south: narrative territorialities, cross cultural currents. London: Routledge, 2020 (no prelo).

JAJl, T. E. Africa in stereo: modernism, music, and pan-Africanism solidarity. New York: Oxford University Press, 2014.

JANOTTIJUNIOR, J. S.; PIRES, V. A. N. Alive online: a ecologia das lives musicais no YouTube em tempos de pandemia. [S.I.: s.n.]: 2021.

KASSABIAN, A. Ubiquitious listening: affect, attention and distributed subjectivity. Berkeley, Los Angeles: University of California Press, 2013.

LIMA, K. O cotidiano de Teresa Cristina, a live de todas as noites. Associação Brasileira de Imprensa, 19 jun. 2020. Disponível em: <http://www.abi.org.br/a-construcao-de-teresa-cristina-o-livede-todas-as-noites/>. Acesso em: 8 out. 2020.

OBICI, G. L. Condições de escuta: mídias e territórios sonoros. Rio de Janeiro: 7Letras, 2008. 
PINACOTECA DE SÃO PAULO. Grada Kilomba: desobediências poéticas. São Paulo: Pinacoteca de São Paulo, 2019. Disponível em: <tinyurl.com/y6hx5nlw>. Acesso em: 11 out. 2020.

SARMENTO, G. Teresa Cristina comemora $1^{\circ}$ patrocínio da carreira: 'Sou invisível desde 1998'. G1, 30 maio 2020. Pop \& Arte. Disponível em: <https://g1.globo.com/pop-arte/musica/ noticia/2020/05/30/teresa-cristina-comemora-1o-patrocinio-da-carreira-sou-invisivel-desde-1998.ghtml>. Acesso em: 10 out. 2020.

SCHAFFER, R. M. O ouvido pensante. São Paulo: Unesp, 1991.

TERESA CRISTINA OFICIAL. Perfil Instagram, 2020. Disponível em: <https://www.instagram. com/teresacristinaoficial/?hl=pt>. Acesso em: 11 out. 2020.

UOL. Zeca Pagodinho fará live no Dia dos Pais: Tô com muita saudade de cantar. UOL, 22 jul. 2020a. Música. Disponível em: <https://entretenimento.uol.com.br/noticias/ redacao/2020/07/22/zeca-pagodinho-fara-live-no-dia-dos-pais-to-com-muita-saudade-de-cantar.htm>. Acesso em: 9 out. 2020.

. Alcione critica presidente da Fundação Palmares: 'Sem noção'. UOL, 4 jun. 2020b. Música. Disponível em: <https://entretenimento.uol.com.br/noticias/redacao/2020/06/04/ alcione-critica-presidente-da-fundacao-palmares-sem-nocao.htm>. Acesso em: 10 out. 2020.

VAN DIJCK, J. The culture of connectivity: a critical history of social media. Oxford, New York: Oxford University Press, 2013.

XAVIER, L. 'Lives' Cátedra Intercom: dois eventos virtuais gratuitos por semana a partir de 5 de maio. Intercom, 4 maio 2020. Disponível em: <https://www. portalintercom.org.br/index.php?/publicacoes/jornal-intercom/2020-2/05-2-2-2/ ano-16-n-513-sao-paulo-04-de-maio-de-2020-issn-1982-372/chamadas-1781/lives-catedra-intercom-dois-eventos-virtuais-gratuitos-por-semana-a-partir-de-5-de-maio>. Acesso em: 8 out. 2020.

Texto recebido em 18/10/2020 e aprovado em 30/01/2021. 